\title{
Acinic cell carcinoma of minor salivary gland origin
}

\author{
Peter Zbaeren, ${ }^{*}$ M.D., Willy Lehmann, ${ }^{*}$ M.D.. Sven Widgren, $\stackrel{+}{\dagger}$ M.D. (Geneva, Switzerland)
}

\begin{abstract}
The occurrence of acinic cell carcinoma in the minor salivary glands appears to be exceptional. A review of the English language literature revealed about 80 previously reported cases. In this paper, the clinical behaviour and pathological findings in three cases are reported.

The tumours took their origin from the hard palate, soft palate and lower lip. The three cases presented with malignant clinical behaviour; all three recurred. In one case the local recurrence was multinodular with capsular infiltration. Two cases developed regional lymph node metastasis, and one metasized to the lung and liver. In one the tumour infiltrated bony structures, and nerve in another. These cases tend to support the belief of some authors that acinic cell 'tumours" are clinically malignant and should be included in the carcinoma group.
\end{abstract}

\section{Introduction}

Acinic cell carcinoma of minor salivary gland origin is exceptional. Relatively few cases have been described in the literature. Most of what is known about this type of tumour has been obtained from studies of acinic cell carcinomas occurring in the major salivary glands. where they make up between two and four per cent of all tumours (Eneroth et al., 1966; Spiro et al. 1978). The first description of this tumour was made by Nasse (1892), who considered the tumour to be benign. Malignant behaviour was ascribed to this tumour in the early $1950 \mathrm{~s}$ (Buxton et al., 1953; Godwin et al., 1954). Since then there has been a tendency for pathologists and surgeons to consider acinic cell tumours as malignant neoplasms. They may recur locally and metastasize to lymph nodes and various organs, essentially the lungs and bones (Abrams et al., 1965). Although acinic cell tumours are classified by the World Health Organization as 'tumour' (Thackray and Sobin. 1972), they are considered in most English publications as carcinomas (Sharkey, 1977).

The purpose of this paper is to present the clinical and pathological findings of three additional cases of acinic cell carcinoma of the minor salivary glands. All three recurred locally, two of them metastasized to regional lymph nodes, and the third to the lung.

\section{Case reports}

Case 1

A 69-year-old healthy woman was admitted to the University ENT department in October 1980 with a firm, fixed mass on the right hard palate measuring approximately $25 \times 20 \times 10 \mathrm{~mm}$. The mass had been present for about one month and was asymptomatic except when the patient placed her upper dental prosthesis in her mouth. No regional lymph nodes were palpated. Routine clinical laboratory data and chest X-ray were normal. A biopsy was performed and revealed an acinic cell carcinoma. The treatment consisted of a hemimaxillectomy.

\section{Pathology report}

The hemimaxillectomy specimen showed a single submuco- sal mass, $2.5 \mathrm{~cm}$ in diameter, histologically made up mainly of solid cords, in some places of medullary sheets, mixed with some tubules and microcyst containing small papillary buds. The cells were small, with little cytoplasm. The nuclei were rather large, round or ovoid, with one or two mucleoli, almost without any mitoses or atypia. At the periphery, the palatal bone was infiltrated in a bland, less often infiltrative fashion (Fig. 1), but there was no effraction. A few venous thromboses were visible beneath the mucosa. The growth pattern of this acinic cell carcinoma was in part medullary, in part acinotubular, according to Batsakis et al. (1979), thus of high grade malignancy.

At routine follow-up five years later, in July 1985, an ipsilateral movable cervical lymph node, measuring $20 \mathrm{~mm}$ in diameter, was detected. A fine needle puncture was positive for an acinic cell carcinoma. In the maxillary cavity no tumour could be detected. A radical neck dissection was performed.

Several large lymph nodes showed metastasis. These deposits were different from the primary tumour: there were quite a large number of cysts with papillae and tubules, both containing bluish mucoid material, and medullary areas. The cells were of varying size with either basophilic or clear cytoplasm, occasionally slightly granular. The nuclei were slightly irregular in shape, but without atypia, and the mitoses were sparse. One lymph node showed capsular penetration by the tumour (Fig. 2). Again these metastases were of high grade malignancy according to Batsakis et al. (1979). Post-operative irradiation of the cervical region completed the treatment.

The patient was well in the succeeding months. In February 1986, a local recurrence in the maxillary cavity was detected. Again wide resection was performed. This recurrence had the same appearance as the primary tumour.

The patient has been well for the last 30 months without local or regional recurrence.

\section{Case 2}

A 58-year-old male was referred to the ENT department of a regional hospital, in November 1976, with a tumour on the right side of the soft palate near the upper pole of the tonsil. It was not painful and had been grown slowly to about one centimetre in diameter over a period of three months. No regional

\footnotetext{
* Department of Otorhinolaryngology, Head and Neck Surgery, †Department of Pathology. University Hospital Geneva, Switzerland. Accepted for publication: 19 April 1991
} 


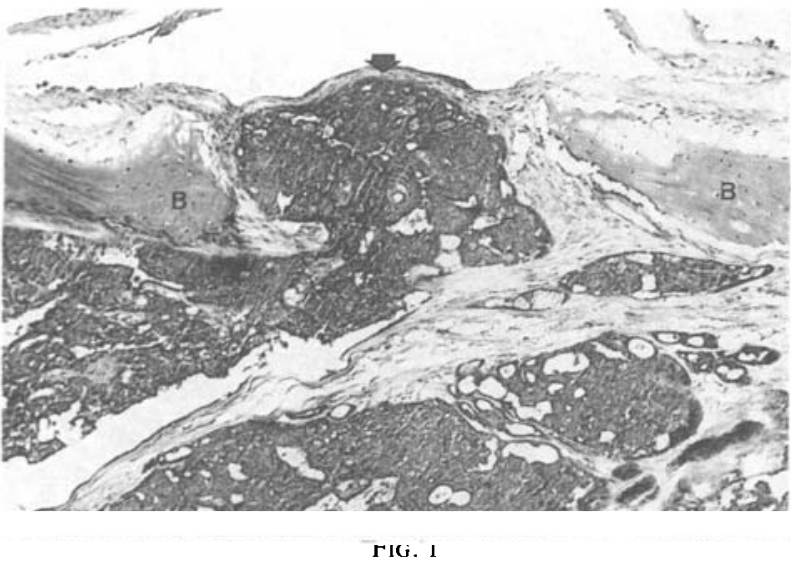

Invasion of the palatal bone (B) by a carcinomatous bud (arrow) (case 1: hacmatoxylin-cosin, $\times 100$ ).

lymph nodes were palpable. The patient was otherwise healthy with no significant past medical history. A surgical biopsy was performed and the tissue obtained was considered to be a pleomorphic adenoma. A wide surgical resection was performed.

\section{Pathology report}

The specimen showed extensive medullary sheets with a few trabecular and tubular structures. The cells were large, polyhedral. cuboid or cylindrical, with a pale eosinophilic or clear cytoplasm, occasionally vacuolated or finely granular. The nuclei were small, without any atypia or mitoses (Fig. 3). In some places, a thin capsule was preserved; in other places the surrounding collagen beneath the mucosa had been infiltrated.

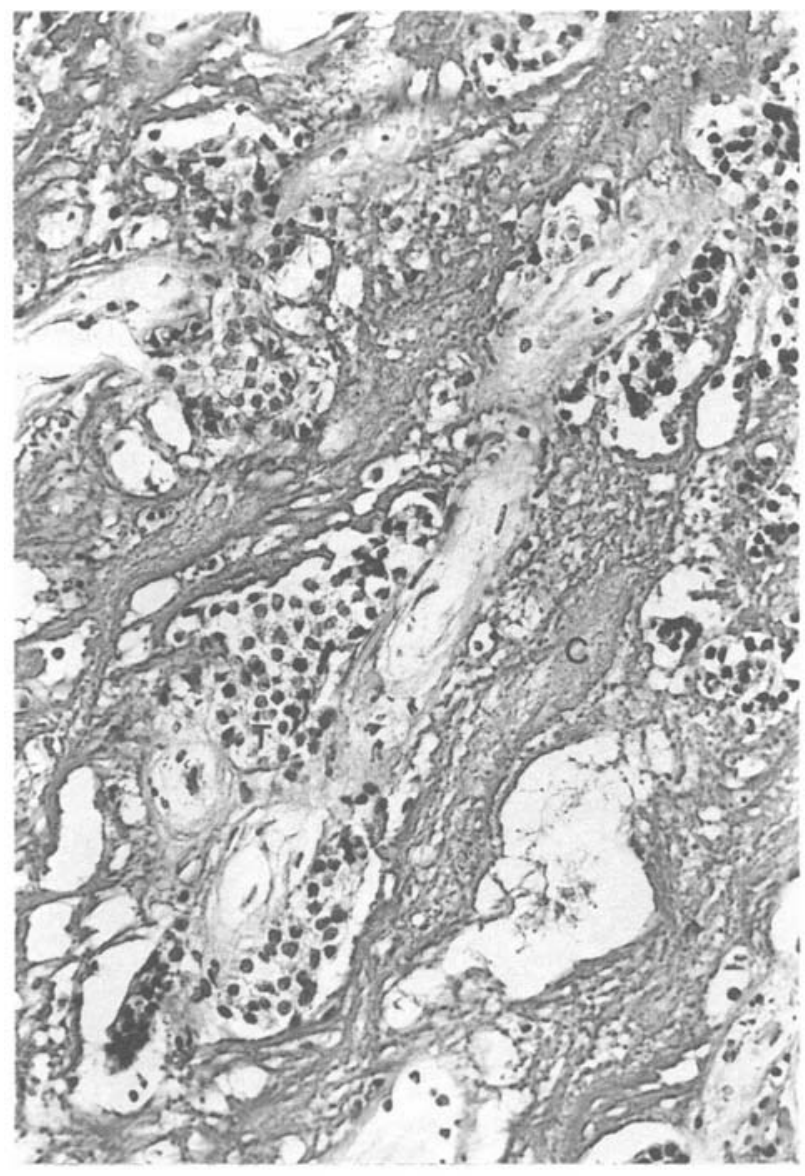

Fig. 3

Submucosal invasion $(\mathrm{C}=$ collagen strands; $\mathrm{T}=$ tumour invasion $)$ (casc 2; hacmatoxylin-cosin, $\times 256$ ).

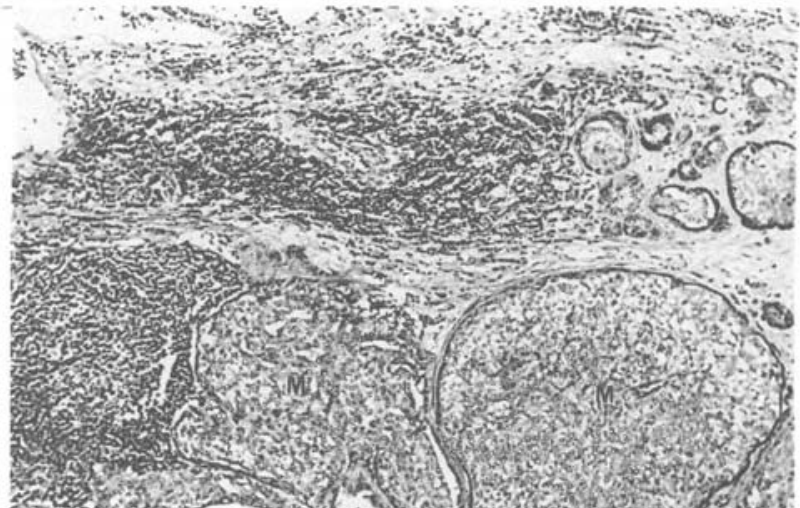

FIG. 2

Lymph node metastasis (M) with capsular infiltration (C) (case ]; hacmatoxylin-cosin, $\times 100)$

The appearance of this acinic cell carcinoma was of the medullary type according to Batsakis et al. (1979), thus of high grade malignancy.

The patient remained well for the following nine years. In August 1985, there was a local recurrence near the scar of the resection. This recurrence had grown slowly over a period of four months and measured about two centimetres in diameter. A mobile ipsilateral submaxillary lymph node, measuring $15 \mathrm{~mm}$ in diameter, could be palpated. A wide surgical resection with extended tonsillectomy and partial neck dissection was performed.

The tumour recurrence was multinodular and had a histological appearance similar to that found in the primary tumour: it was made up of several circumscribed nodules with predominance of medullary structures, but also with a rather large trabecular component. The nuclei were small and regular, without any atypia or mitoses. The neck dissection specimen contained a largely destroyed metastasis of the same histological type as that of the primary tumour recurrence. At the periphery of a tumour node, a vein was occupied by a carcinomatous thrombus (Fig. 4)

The patient has been well for the last 36 months without local or regional recurrence.

\section{Case 3}

A 48-year-old male was admitted to the University ENT department, in November 1985 with a tumour on the lower lip measuring one centimetre in diameter, which had grown slowly over a period of six months. It was asymptomatic and no regional lymph nodes were palpable. Routine clinical laboratory data and chest X-ray were normal. A wide surgical resection with histological frozen section control of the margins and partial ipsilateral neck dissection were performed.

\section{Pathology report}

The resected specimen contained a submucosal ovoid tumour, $9 \mathrm{~mm}$ in its largest diameter, soft to elastic consistency, pinkish white in colour and well defined. The tumour consisted of solid sheets and cords, with a few acinic nests, corresponding to the acinar and trabecular type of acinic cell carcinoma described by Perzin and LiVolsi (1979). The cells were rather large, poorly eosinophilic, occasionally slightly vesiculated or granular. These granules were PAS positive, negative after diastase, not stained by Alcian blue. The nuclei were relatively large, ovoid or lobulated, with evident atypia and several mitoses (Fig. 5). A few necrotic areas were present within the trabeculae. among which there were fibrotic sheets. At the periphery of the tumour, some salivary gland lobules with slight fibrosis were visible. 


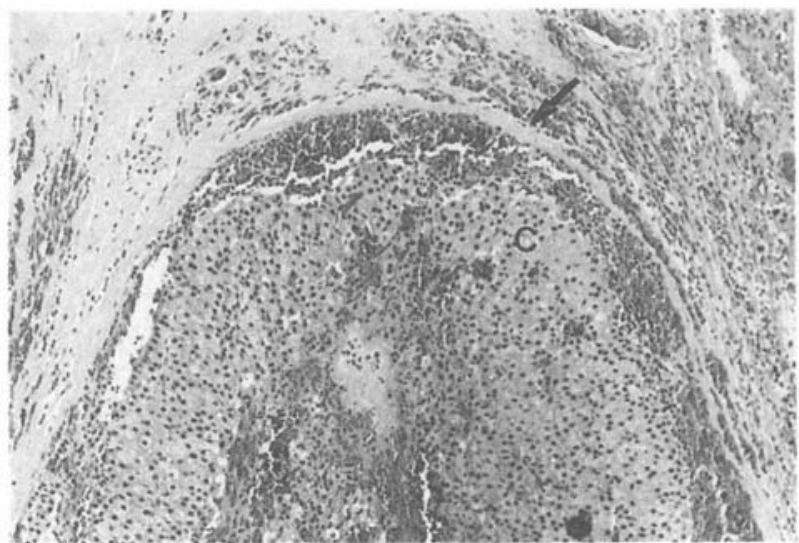

Fig. 4

Carcinomatous thrombus in vein $(\mathrm{C}=$ carcinoma; arrow: wall of vein) (case 2; hacmatoxylin eosin, $\times 100$ ).

Thus this acinic cell carcinoma, difficult to integrate in the classification of Batsakis, et al. (1979), seems to be in part of a high grade type of malignancy because of the presence of nuclear atypia and several mitoses. No lymph node metastasis was found in the neck dissection specimen.

In February 1986, a local recurrence measuring $5 \mathrm{~mm}$ in diameter was again widely resected. The loss of tissue was covered with a forehead skin flap. The histopathological features were similar to those of the primary tumour. Tumour cells were also found in a branch of the mandibular nerve (Fig. 6). The surgical margins were free of tumour. This tumour showed very aggressive clinical behaviour, and therefore treatment was completed by a course of irradiation. Eight months later, the patient developed liver and lung metastases (Fig. 7). He died in October 1987 with multiples metastases but without local or regional recurrence.

\section{Discussion}

Acinic cell carcinoma is extremely rare in extraparotid sites, particularly in the minor salivary glands where our three tumours were located. Approximately 80 cases only have been reported in the literature (Suzuki and Hendersen, 1968; Chen et al., 1978; Fermont, 1979; Ferlito, 1980; Gardner et al., 1980; Ellis and Corio, 1983). Most were single case reports and a number of cases were included in papers on acinic cell carcinoma of the major salivary glands. Spiro et al., (1973) in a

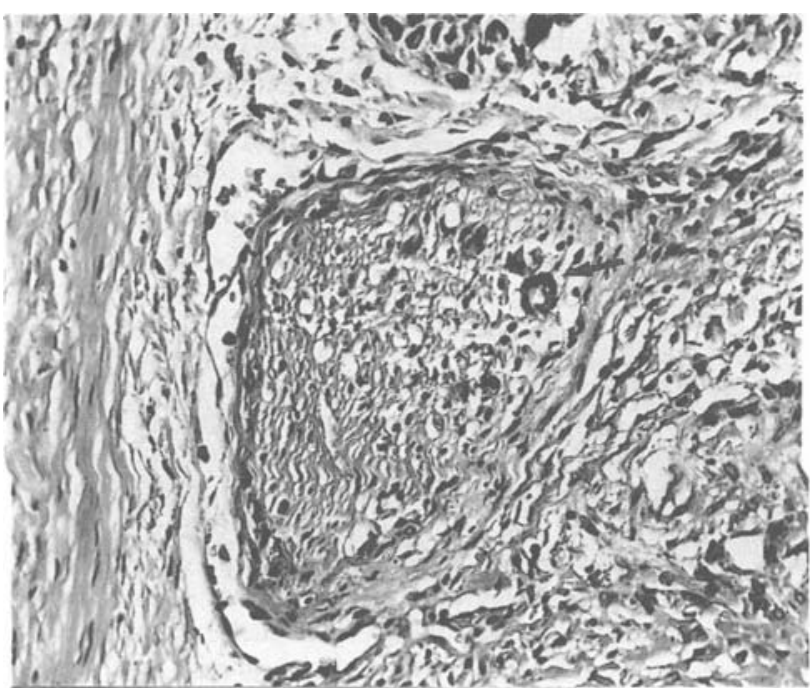

FIG. 6

Invasion of a nerve by carcinoma (arrow) (case 3; haematoxylin$\operatorname{cosin}, \times 256)$

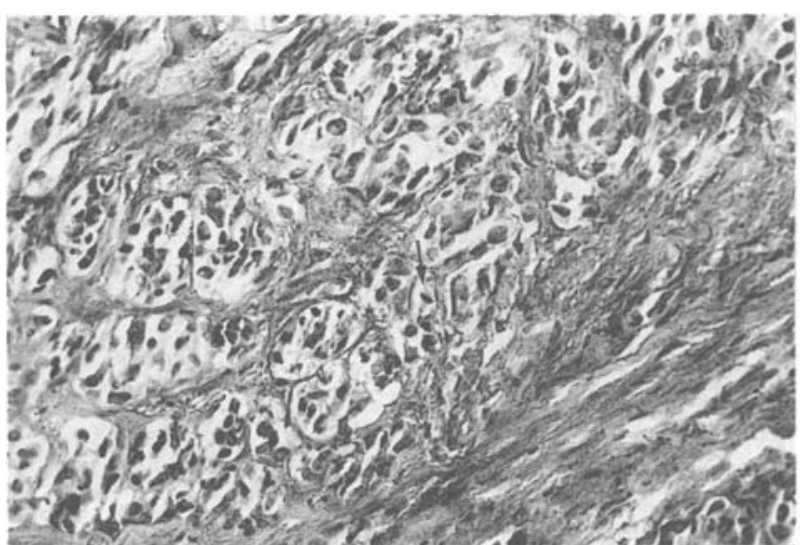

Fig. 5

Typical appearance of acinic cell carcinoma with tumour strands showing nuclear atypia and one mitosis (arrow) (case 3: haematoxylin-cosin, $\times 256$ )

review of 570 minor salivary gland tumours seen at the Memorial Sloan Kettering Cancer Center in New York, from 1939 to 1968 , found only two cases of acinic cell carcinoma. Seifert $e t$ al. (1980) saw only one acinic cell carcinoma in his collection of 160 accessory salivary gland tumours, whereas. Brocheriou and Bertram (1987) had only two in a series of 370 minor salivary gland tumours. Acinic cell carcinomas have been observed in a wide variety of sites: palate, buccal mucosa. lip. tongue, and rarely in the retromolar or gingival region. mandible and paranasal sinuses (Manace and Goldman, 1971: Abrams and Melrose, 1978; Inoue et al., 1984).

The three cases presented here were characterized by malignant clinical behaviour: they recurred locally, cases 1 and 2 developed lymph node metastasis; case 3, lung and liver secondaries. The time lapse between initial treatment and recurrence was five and nine years in cases 1 and 2 , some months in case 3 which was characterized by a very aggressive behaviour. One tumour invaded bone (case 1), a recurrence was multinodular (case 2), the recurrence in the third case invaded a nerve. It has been postulated that acinic cell carcinoma of the minor salivary glands is histologically less aggressive than that of the parotid gland (Abrams and Melrose, 1978). The present cases do not confirm this assumption. The histopathological features

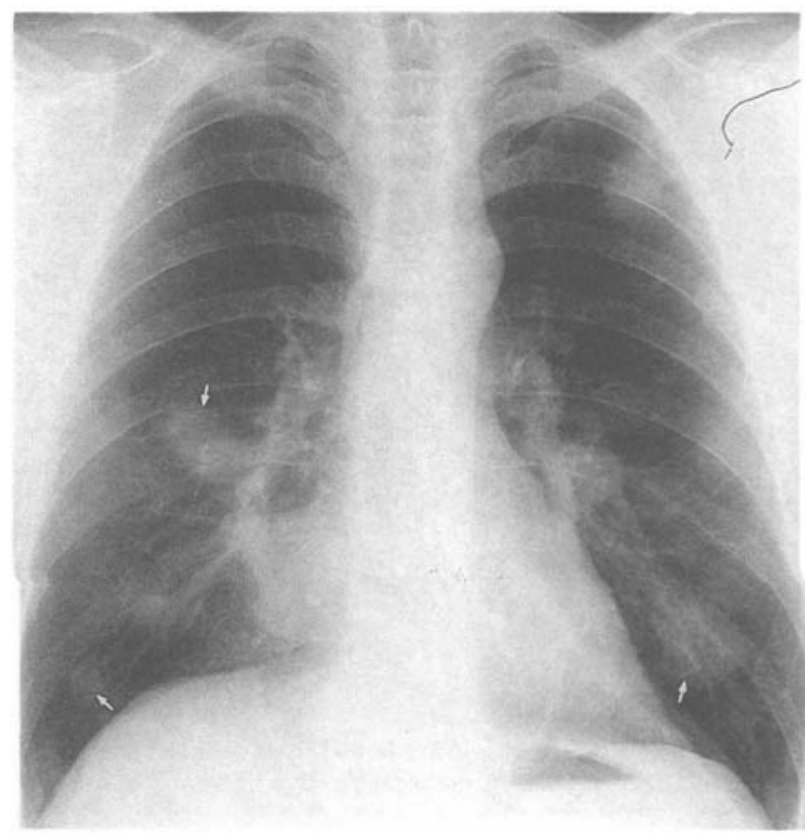

FIG. 7

Metastasis of the lungs (arrows) (case 3). 
seen in the present cases were essentially the same as those described in the literature on acinic cell carcinomas of major salivary glands (Abrams et al., 1965; Batsakis et al., 1979). Cytological features usually associated with malignancy such as nuclear and cellular pleomorphism, increased and abnormal mitotic activity and nuclear hyperchromatism were often not demonstrable. Most clinicopathological analyses of acinic cell carcinomas have concluded that histopathological features are unreliable in predicting biological behaviour. Batsakis et al. (1979) have described a classification of low-grade and highgrade malignancies of these tumours. However, they mentioned that the fallibility of such a grading system is characterized by the occasional aggressive behaviour of low-grade tumours. Our case 3 was quite difficult to integrate into the classification of Batsakis et al. (1979); it was finally considered as a high grade type of malignancy; however its histological appearance does not fit well into the histological types described by these authors and corresponds better to that described by Perzin and LiVolsi (1979).

Considering the histogenesis, a pluripotential duct cell origin has been suggested (Abrams et al., 1965; Chen et al., 1978) because of the presence of tumour cells that present the appearance of intercalated duct cells as well as transitional features between the latter and acinic cells. The three cells presented would suggest once more that acinic cell 'tumours' are malignant with a considerable tendency to recur and to metastasize. Recurrences and metastasis may occur after variable lengths of time, occasionally after several years. The best management of these neoplasms, at present, lies in radical surgical removal at the time of initial treatment.

\section{Acknowledgements}

The authors would like to thank Dr C. Ruchti, Institute of Pathology, Berne, Switzerland, for the histological slides of case 2 .

\section{References}

Abrams, A. M. . Cornyn, J., Scofield, H. H., Hansen, L. S. (1965) Acinic cell adenocarcinoma of the major salivary glands. A clinicopathologic study of 77 cases. Cancer, 18: 1145-1162.

Abrams, A. M., Melrose, R. J. (1978) Acinic cell tumors of minor salivary gland origin. Oral Surgery, Oral Medicine, Oral Pathology, 46: 220-233.

Batsakis, J. G., Chinn, E. K., Weimert, T. A., Work, W. P., Krause, C. J. (1979) Acinic cell carcinoma: A clinicopathologic study of 35 cases. Journal of Laryngology and Otology, 93: 325-340.

Brocheriou, C., Bertran, J. C. (1987) In Cancers des voies aérodigestives supérieures (Brugèrc, J.). Flammarion Médecine Sciences: Paris.

Buxton, R. W., Maxwell, J. H., French, A. J. (1953) Surgical treat- ment of epithelial tumors of the parotid gland. Surgery, Gynecology and Obstetrics, 97: 401-416.

Chen, S. Y., Brannon, R. B., Miler, A. S., White, D. K., Hooker, S. P. (1978) Acinic cell adenocarcinoma of minor salivary glands Cancer, 42: 678-685.

Ellis, G. L., Corio, R. L. (1983) Acinic cell adenocarcinoma. A clinicopathologic analysis of 294 cases. Cancer, 52: 542-549.

Eneroth, C. M., Hamberger, C. A., Jakobsson, P. A. (1966) Malignancy of acinic cell carcinoma. Annals of Otology, Rhinology and Laryngology, 75: 780-792.

Ferlito, A. (1980) Acinic cell carcinoma of minor salivary glands. Histopathology, 4: 331-343.

Fermont, D. C. (1979) Acinic cell carcinoma of intraoral salivary gland origin. Journal of Laryngology and Otology, 93: 423-426.

Gardner, D. G., Bell, M. E. A., Wesley, R. K., Wysocki, G. P. (1980) Acinic cell tumors of minor salivary glands. Oral Surgery, Oral Medicine, Oral Pathology, 50: 545-551

Godwin, J. T., Foote, F. W., Frazell, E. L. (1954) Acinic cell ade nocarcinoma of the parotid gland. Report of 27 cases. American Journal of Patholgoy, 30: 465-477.

Inouc, T. Shimono, M., Yamamura, T., Saito, I., Watanabe, O. Kawahara, H. (1984) Acinic cell carcinoma arising in the glossopalatine glands: A report of two cases with electron microscopic observations. Oral Surgery, Oral Medicine, Oral Pathology, 57: $398-407$.'

Manace, E. D., Goldman, J. L. (1971) Acinic cell carcinoma of the paranasal sinuses. Laryngoscope, 81: 1074-1082.

Nasse, D. (1892) Die Geschwülste der Speicheldrüsen und verwandte Tumoren des Kopfes. Archiv für klinische Chirurgie, 44: 232-302.

Perzin, K. H., LiVolsi, V. A. (1979) Acinic cell carcinomas arising in salivary glands. A clinicopathologic study. Cancer, 44: 1434-1457.

Seifert, G., Rieb, H., Donath, K. (1980) Klassifikation der Tumoren der kleinen Speicheldrüsen. Pathologische Analyse von 160 Tumoren. Laryngologic Rhinologic, 59: 379-400.

Sharkey, R. E. (1977) Systematic evaluation of the World Health Organization classification of salivary gland tumors. A clinicopathologic study of 366 cases. American Journal of Clinical Pathology, 67: 272-278.

Spiro, R. H., Koss, L. G., Hajdu, S. I., Strong, E. W. (1973) Tumors of salivary gland origin. A clinicopathologic study of 492 cases. Cancer, 31; 117-129.

Spiro, R. H., Huvos, A. G., Strong. E. W. (1978) Acinic cell carcinoma of salivary origin. A clinicopathologic study of 67 cases. Cancer, 41: 924-935.

Suzuki, H., Henderson, R. (1968) Acinic cell carcinoma of the sublingual gland. Archives of Otolaryngology, 87: 146-149.

Thackray, A. C., Sobin, L. H. (1972) Histological typing of salivary gland tumors. WHO Int Histology Classification, Tumors 7: Geneva.

Address for correspondence:

Peter Zbären, M.D.,

Clinic of Otorhinolaryngology and Head and Neck surgery,

University Hospital

Geneva,

Switzerland.

Key words: Salivary gland neoplasms; Acinic cell carcinoma 